${ }^{1}$ Smyth CJ. Angina pectoris and myocardial infarction as complications of myxedema: with especial reference to the danger of treatment with thyroid preparations. Am Heart $\mathcal{f}$ 1938;15:652-60.

2 Steinberg AD. Myxedema and coronary artery disease-a comparative autopsy study. Ann Intern Med 1968;68:338-44.

${ }^{3}$ Keating FR, Parkin TW, Selby JB, Dickinson LS. Treatment of heart disease associated with myxedema. Prog Cardiovasc Dis 1961 ;3:364-81.

- Lotti G, Delitala G, Devilla L, Alagna S, Masala A. Reduction of plasma triiodothyronine (T3) induced by propranolol. Clin Endocrinol (Oxf) 1977;6:405-10.

5 Levine HD. Compromise therapy in the patient with angina pectoris and hypothyroidism. A clinical assessment. $A m \mathcal{F} \mathrm{Med} 1980 ; 69: 411-7$

- Paine TD, Rogers WJ, Baxley WA, Russell RO. Coronary arterial surgery in patients with incapacitating angina pectoris and myxedema. $A m \mathcal{J}$ Cardiol $1977 ; 40: 226-31$.

${ }^{7}$ Hay ID, Duick DS, Maloney JD, Vlietstra RE, Pluth JR. Thyroid hormone therapy in hypothyroid patients undergoing coronary angiography and aortocoronary bypass graft surgery. In: Stockigt JR, Nagataki S, eds. Thyroid research VIII. Canberra: Australian Academy of Science, 1980:526-8.

\section{Adverse drug reactions}

To be accepted as effective and reasonably safe a drug has to pass a series of prolonged and expensive tests. Yet when looking at its adverse effects doctors seem to apply double standards. While one or two unconfirmed case reports may be enough to label a drug as having unusual toxicity, little is known of the incidence of the less spectacular adverse effects of drugs in widespread general use. The monitored release schemes have not been very productive, and the yellow card system is grossly underused by all doctors. ${ }^{1}$

Adverse drug reactions are often classified into two types. Type 1, or type A, effects are those effects to be expected from pharmacological properties of the drug, such as bleeding when taking warfarin or hyperkalaemia with spironolactone. Type 2, or type B, reactions are the unexpected ones, which, while less common than type 1 reactions, usually carry a much higher morbidity and mortality. Rawlins has given more details of this classification in a recent review in the $B M$ F. $^{2}$ Most drug reactions are mild, but a few may be severe enough to threaten life, especially in patients with serious underlying disease. Some years ago in the United States up to 140000 deaths were said to occur each year from adverse reactions to drugs, ${ }^{34}$ and one-seventh of all hospital days were said to be devoted to the care of patients suffering from drug toxicity. ${ }^{5}$ These statements are now seen as exaggerations, but considerable alarm was caused at the time. The trouble was caused partly by lack of definition of an adverse drug reaction. Clear definitions are now accepted which categorise drug reactions as definite, probable, possible, conditional, and doubtful. ${ }^{3}$ Medical journals have helped to minimise unnecessary anxiety by printing reports in only the first two or, at most, three categories.

Using these criteria, comprehensive studies (such as those carried out by the Boston Collaborative Drug Surveillance Program) have shown that among patients admitted to an acute medical ward adverse drug reactions will be seen in $10 \%$ to $15 \%$ of patients ${ }^{6}{ }^{7}$ but that most will be mild and, at worst, only an inconvenience to the patient. Life-threatening reactions among such patients have been reported to occur in $3 \%$ of patients in American hospitals, ${ }^{4}$ but in a combined British and American study Lawson and his colleagues ${ }^{8}$ found only 28 instances of life-threatening reactions among 2580 medical inpatients $(1 \cdot 1 \%)$. These reactions were more common in patients with known cancer, and hyperkalaemia and hypokalaemia were the most common drug-induced reactions. In a further study ${ }^{9}$ Lawson and his colleagues found 73 cases $\underline{T}$ of severe hypokalaemia over a three-year period, with a $\$ particularly high incidence in patients with myeloid leukaemia. $\frac{8}{\varsigma}$ In nearly 27000 carefully monitored patients fewer than one in 1000 were considered to have died as the result of an adverse drug reaction. ${ }^{10}$ Digoxin and cytotoxic agents figured prominently in this series, and six of the 24 deaths might have been preventable.

What about the admission to hospital of patients primarily because of an adverse drug reaction ? In four recent studies ${ }^{11-14}$ the results were consistent, with $2.9 \%, 3.7 \%, 4.1 \%$, and $5 \cdot 7 \%$ of admissions respectively being primarily due to an adverse drug reaction. Admissions to intensive care units might be thought to be a measure of more severe drug reactions, but the data can be misinterpreted. In a study in France $1.8 \%$ of admissions over a 10 -year period were due to drug toxicity. ${ }^{15}$ In another French study Trunet and his colleagues ${ }^{16}$ found that 40 out of 325 admissions to an intensive care unit were due to iatrogenic disease, but this high proportion was probably due to the admission of most patients from surrounding hospitals rather than from the patient's home. Adverse drug reactions are not solely the province of hospital doctors, ${ }^{17}$ and one in 40 of consultations in general practice is due to iatrogenic disease. ${ }^{18}$

Certain groups of patients are at higher-than-average risk of $\dot{\infty}$ developing an adverse drug reaction. These reactions are more common in women than in men, ${ }^{11} 14$ particularly white women rather than black women, ${ }^{11}$ and there is increasing interest in the genetic contribution to adverse drug reactions. ${ }^{19}$ Adverse reactions are more likely in the elderly and in patients given multiple drug treatment. ${ }^{1314}$ The disease itself will also contribute to the likelihood of an adverse drug reaction, drug reactions being more likely in patients with impaired renal function $^{13} 14$ and with cancer. ${ }^{916}$ In most reports certain drugs stand out and we should be particularly careful in their use: these include aspirin, digoxin, diuretics, antibiotics, anticoagulants, and corticosteroids and other immunosuppressive drugs.

In general, severe adverse reactions are uncommon, and the benefits of drug treatment usually outweigh the disadvantages. Nevertheless, most studies show that $25 \%$ of these adverse drug reactions are preventable. ${ }^{101314}$ What can we as prescribing doctors do to prevent these reactions ? Firstly, we must all have a higher index of suspicion. This does not mean rushing into print at the slightest provocation, but thinking that an unusual or unexpected event may be due to drug toxicity. If in doubt, a yellow adverse drug reaction card should be filled in and posted to the Committee on Safety of Medicines. Secondly, we should take particular care in our use of highrisk drugs and in high-risk patients. Finally, local schemes for monitoring adverse drug reactions both in hospitals and in general practice will keep the possibility at the front of our minds. Such a scheme was mooted in these columns two years $\mathrm{ago}^{20}$ and has in general been greeted with masterly inactivity. Perhaps better progress can be made in the next two years.

1 Inman WHW. Detection and investigation of adverse drug reactions. In: Davies DM, ed. Textbook of adverse drug reactions. London: Oxford University Press, 1977:41-53.

${ }^{2}$ Rawlins MD. Adverse drug reactions. Br Med 7 1981 ;282:974-6.

${ }^{3}$ Karch FE, Lasagna L. Adverse drug reactions: a critical review. $\mathfrak{F} A M A$ $1975 ; 234: 1236-41$.

4 Jick H. Drugs-remarkably nontoxic. N Engl f Med 1974 ;291 :824-8.

5 Melmon KL. Preventable drug reactions-causes and cures. $N$ Englf Med 응 $1971 ; 284: 1361-8$.

${ }^{6}$ Hurwitz N, Wade OL. Intensive hospital monitoring of adverse reactions to drugs. Br Med f 1969 ; i :531-6. 
7 McMahon KA, Frewin DB, Easterbrook EG, Hender EA, Lee TI, Penhall RK. Adverse reactions to drugs-a 12-month hospital survey. Aust NZ F Med 1977;7:382-5.

${ }^{8}$ Lawson DH, Hutcheon AW, Jick H. Life threatening drug reactions amongst medical in-patients. Scott Medf 1979;24:127-30.

9 Lawson DH, Henry DA, Lowe JM, Gray JMB, Morgan G. Severe hypokalemia in hospitalised patients. Arch Intern Med 1979;139:98780.

10 Porter J, Jick $\mathrm{H}$. Drug-related deaths among medical inpatients. $\mathcal{F} A M A$ $1977 ; 237: 879-81$.

${ }^{11}$ Caranasos GJ, Stewart RB, Cluff LE. Drug-induced illness leading to hospitalisation. $\mathcal{F} A M A 1974 ; 228: 713-7$.

12 Miller RR. Hospital admissions due to adverse drug reactions. A report from the Boston Collaborative Drug Surveillance Program. Arch Intern Med $1974 ; 134: 219-23$

${ }^{13}$ Levy M, Lipshitz M, Eliakim M. Hospital admissions due to adverse drug reactions. Am $\mathcal{f}$ Med $S c i$ 1979;228:49-56.

14 Levy M, Kewitz H, Altwein W, Hillebrand J, Eliakim M. Hospital admissions due to adverse drug reactions: comparative study from Jerusalem and Berlin. Eur F Clin Pharmacol 1980;1 7:25-31.

${ }^{15}$ Auzépy Ph, Durocher A, Gay R, et al. Accidents médicamenteux graves chez l'adulte: incidence actuelle dans le recrutement des unités de réanimation. Nouv Presse Med 1979;8:1315-8.

16 Trunet P, Le Gall J-R, Lhoste F, et al. The role of iatrogenic disease in admissions to intensive care. $\mathcal{F} A M A 1980 ; \mathbf{2 4 4}: 2617-20$.

17 Martys CR. Adverse reactions to drugs in general practice. $\mathrm{Br} M e d f$ 1979;ii:1194-7.

${ }^{18}$ Mulroy R. Iatrogenic disease in general practice: its incidence and effects. Br Med f 1973;ii:407-10

19 Panayi GS, Wooley P, Batchelor JR. Genetic basis of rheumatoid disease; HLA antigens, disease manifestations, and toxic reactions to drugs. Br Med f 1978;ii:1326-8.

20 Anonymous. Drug toxicity studies and the clinical pharmacologist. BrMed F 1979;ii:1246.

\section{Trigeminal neuralgia: treat but do not prolong}

New techniques ${ }^{1-5}$ for the management of trigeminal neuralgia have made neurologists revise their approach-but the initial assessment must still be a clinical one. At the first interview the physician should record carefully the occurrence of paroxysmal, lancinating pains, provoking stimuli, trigger points, and direction of spread ${ }^{6}$ before the history becomes contaminated by injudicious leading questions or chronic burning facial pain develops. ${ }^{4}$ Dental malocclusion and temporomandibular dysfunction, especially in edentulous patients, may precipitate attacks of trigeminal neuralgia and should be recognised and treated. ${ }^{7}$ The presence of a malignant tumour, such as an infiltrating lesion at the base of the skull, needs to be excluded. ${ }^{5}$ In most cases the diagnosis is confirmed by the response to carbamazepine, starting with $100 \mathrm{mg}$ (or even $50 \mathrm{mg}$ ) doses in elderly patients and increasing the number of tablets rapidly until relief is obtained. If intolerance develops, phenytoin $100 \mathrm{mg}$ twice daily can be given concomitantly with chlorpromazine or a tetracyclic antidepressant and the patient referred for surgical evaluation.

Referral should also be considered for patients with recurrent bouts of trigeminal neuralgia, even if relief is obtained with carbamazepime, lest permanent relief be postponed until the patient is too infirm to tolerate a major procedure. ${ }^{4}$ Just occasionally peripheral neurectomy or injection is indicated: in the terminally ill, to aid diagnosis; or to provide prompt relief so that a patient with severe loss of weight may have time to improve her nutritional state before operation. ${ }^{5}$ If the pain is limited to the supraorbital, supratrochlear, or infraorbital nerve territories, a peripheral neurectomy may provide relief, leaving residual numbness but avoiding the risk of corneal ulceration. ${ }^{5}$
Trigeminal neuralgia occurs most commonly in the sixth and seventh decades, but may develop at any time from the fifth to the ninth. ${ }^{4}$ Most cases are idiopathic but a familial tendency has been reported. ${ }^{8}$ Multiple sclerosis may be a cause, especially in the third and fourth decades: it accounts for $2 \%$ of all patients with trigeminal neuralgia. Herpes zoster and trauma may also result in symptomatic trigeminal neuralgia. Whatever their cause, the symptoms respond to the same treatment as idiopathic trigeminal neuralgia. Pathological changes in the idiopathic form are present at three sites: vascular anomalies and other compressive lesions occur around the posterior rootlets at their entry zone into the pons ${ }^{910}$; "aging changes" at the level of the trigeminal ganclia cause disruption and proliferation of myelin sheaths, swelling of mitochondria, and degeneration of unmyelinated fibres ${ }^{11}$; and localised lesions have recently been described, including osteonecrosis and marrow fibrosis of parts of the jaw. ${ }^{12}$

Microvascular decompression is now the preferred major surgical procedure in selected young patients, because it can provide long-term relief of pain without concomitant trigeminal anaesthesia. Dandy, ${ }^{9}$ who developed the posterior fossa approach, had noted vascular loops compressing the posterior root in $30 \%$ of 215 patients, tumour in $5 \%$, aneurysms in $3 \%$, and cavernous angiomas in $2 \%$. Extending these observations with the operating microscope, Jannetta ${ }^{10}$ believes that vascular loops or other compressive abnormalities affecting the posterior roots are present in nearly all patients with trigeminal neuralgia and that their careful dissection can relieve pain in $96 \%$ of patients. Where such decompression is not possible a limited rhizotomy may be performed. ${ }^{1}$ The hazards of microvascular decompression are those of any major operation on the posterior fossa and include air embolism and postoperative headache. ${ }^{2}$

Percutaneous radiofrequency trigeminal neurolysis was developed by Sweet and Wepsic, ${ }^{13}$ and consists of controlled thermocoagulation of the small, poorly myelinated pain fibres with the relative preservation of touch sensation carried by the more heavily myelinated fibres. The procedure, initially under local anaesthesia, resembles previous injection techniques with the insertion of a thin needle through the foramen ovale. Intravenous methohexitone is usually given to cover the application of the coagulating current. The technique carries minimal risk and has a very low morbidity. The initial success rate is $88-90 \%,{ }^{2}$ and a further $5 \%$ of patients will be improved by further application. The late recurrence rate is $10 \%{ }^{3}$ Failure may occur if the operator cannot penetrate the foramen ovale. The incidence of corneal anaesthesia varies from 1.5 to $13 \%$ and anaesthesia dolorosa or severe dysaesthesia from 5 to $11 \% \%^{214}$ Though these complications cannot be ignored their incidence is far lower than with refined injection techniques using hyperbaric $5 \%$ phenol in glycine, ${ }^{5}$ and the relief obtained is more lasting.

1 Tarlov E. Percutaneous and open microsurgical techniques for relief of refractory tic doloureux. Surg Clin North Am 1980;60 :593-607.

2 Apfelbaum RI. A comparison of percutaneous radiofrequency trigeminal neurolysis and microvascular decompression of the trigeminal nerve for the treatment of tic douloureux. Neurosurgery $1977 ; \mathrm{i}: 16-21$.

3 Wepsic JC. Tic douloureux: etiology, refined treatment. $N$ Engl $7 \mathrm{Med}$ $1973 ; 288: 680-1$

- Bayer DB, Stenger TG. Trigeminal neuralgia: an overview. Oral Surg $1979 ; 48: 393-9$

${ }^{5}$ Sweet WH. Trigeminal neuralgia. In: Alling CC, Mohan PE, eds. Facial pain. Philadelphia: Lea and Febiger, 1977:71-94.

${ }^{6}$ Henderson WR. Trigeminal neuralgia: the pain and its treatment. $\mathrm{Br} \mathrm{Med}$ f $1967 ; \mathrm{i}: 7-15$.

7 Blair GAS, Gordon DS. Trigeminal neuralgia and dental malocclusions Br Med f 1973;iv:38-40.

${ }^{8}$ Herzberg L. Familial trigeminal neuralgia. Arch Neurol 1980 ;37:285-6. 